\title{
Extending the limits for mitral valve replacement in low-weight infants using a stented bovine jugular vein graft
}

\author{
Matteo Trezzi, MD, Enrico Cetrano, MD, Antonio Albano, MD, and Adriano Carotti, MD, Rome, Italy
}

See related commentary on pages 731-2.

Mitral valve (MV) disease in infants is most commonly seen in the setting of a partial or complete atrioventricular septal defect, multiple left-sided obstructive lesions, or isolated valve dysplasia. When MV replacement is indicated, options are limited due to prostheses diameter and design with morbidity and mortality rates far from negligible. ${ }^{1,2}$ We report our experience with the Melody valve (Medtronic, Minneapolis, Minn), for MV replacement in high-risk, low-weight infants with MV disease not amenable to surgical repair. This technique is a modification of that originally proposed by Emani and colleagues. ${ }^{3}$

\section{CLINICAL SUMMARY}

Patient 1, aged 3 months and weighing $2.7 \mathrm{~kg}$, with a diagnosis of partial atrioventricular septal defect and parachute MV, underwent ostium primum closure as a neonate and 2 subsequent MV repair attempts for severe valvular regurgitation. Patient 2, aged 30 days and weighing $3.0 \mathrm{~kg}$, with a diagnosis of critical aortic stenosis, MV arcade, and endocardial fibroelastosis, underwent unsuccessful percutaneous balloon aortic valvuloplasty and subsequent neonatal Ross-Konno procedure. MV dysfunction was not addressed at the time of the first operation. In both cases, the need for MV replacement was indicated by severe MV regurgitation with failure to wean from mechanical ventilation. The MV was approached transeptally in patient 1 and through a left atriotomy in patient 2 . In both patients the native valve was totally excised and the subvalvular apparatus removed. Intraoperative MV annular diameter after leaflets excision was 13 and $11 \mathrm{~mm}$ in patient 1 and patient 2 , respectively. The original $3-\mathrm{cm}$ stented

\footnotetext{
From the Division of Pediatric Cardiac Surgery, Children's Hospital Bambino Gesù I.R.C.C.S., Rome, Italy.

Disclosures: Authors have nothing to disclose with regard to commercial support. Received for publication April 8, 2015; revisions received May 20, 2015; accepted for publication June 6, 2015; available ahead of print July 14, 2015

Address for reprints: Matteo Trezzi, MD, Division of Pediatric Cardiac Surgery, Children's Hospital Bambino Gesù I.R.C.C.S., Piazza S. Onofrio 4, 00165 Rome, Italy (E-mail: trezzim@hotmail.com).

J Thorac Cardiovasc Surg 2015;150:729-30

$0022-5223 / \$ 36.00$

Copyright (c) 2015 by The American Association for Thoracic Surgery http://dx.doi.org/10.1016/j.jtcvs.2015.06.019
}

Melody valve was shortened to $2 \mathrm{~cm}$ by bending the proximal and distal row of crowns. ${ }^{4}$ The valve was temporarily crimped down to $10 \mathrm{~mm}$ to facilitate insertion into the annulus and suture fixation of the distal stent to the left ventricle free wall was performed. Annular fixation was achieved with multiple interrupted 6-0 pledgeted polyamide stitches passed around the wired stent without adding a pericardial sewing cuff (Figure 1). The valve was expanded in position with a 12-mm balloon (inflated to $4 \mathrm{~atm}$ ) in both cases, and the sutures were tied. A 3-mm interatrial opening in both patients for future catheter-based interventions was created. Postoperative echocardiography showed good function of the mitral valve (gradients of 3 and 2 $\mathrm{mm} \mathrm{Hg}$, respectively) in the absence of left ventricular outflow obstruction or paravalvular leaks. Both patients had an uneventful recovery and were discharged home: they remained in normal sinus rhythm with no conduction disturbances and achieved normal somatic growth. The 5-month follow-up transthoracic echocardiograph showed transvalvular gradients of 6 and $8 \mathrm{~mm} \mathrm{Hg}$, respectively, with trivial regurgitation. Subsequent valve expansion was not required in either patient, but it has been demonstrated to be feasible as a satisfactory maintenance of prosthetic function.

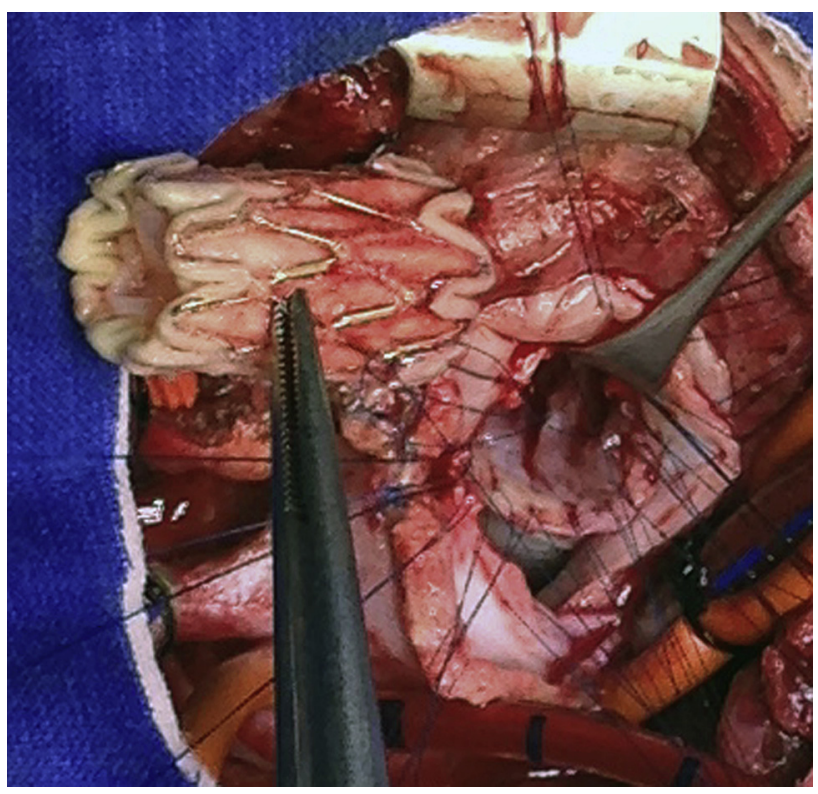

FIGURE 1. Intraoperative view. 

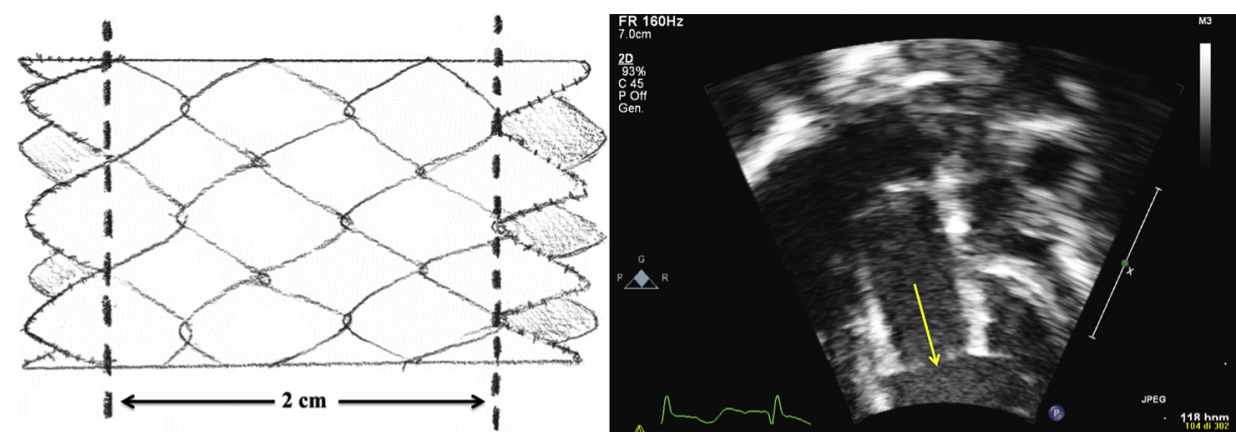

FIGURE 2. Left, Melody valve. Right, Four-chamber view of the Melody valve in patient 1 . Note the length of the stent $(\approx 1 \mathrm{~cm})$ protruding into the left ventricle (arrow).

\section{DISCUSSION}

The Melody valve has several advantages over other commercially available prostheses, such as large effective orifice area index, avoidance of anticoagulation, and ease of implantation in patients with severely hypoplastic MV annuli. ${ }^{5}$ We do not recommend any disruption of the stent crowns at the time of implantation because this adds complexity to the procedure and may lead to future valve failure. For these reasons we achieved valve shortening by bending the proximal and distal rows of prongs. Left ventricular outflow obstruction was not observed due to the minimized edge of the stent protruding into the ventricle ( $1 \mathrm{~cm}$ in length) (Figure 2). We do not recommend preservation of the entire anterior leaflet and/or its subvalvular apparatus. We believe that in small patients this could potentially lead to postoperative left ventricular outflow obstruction. Nonetheless, minimal leaflet tissue should be spared, due to the likelihood of atrioventricular node injury during suture placement, particularly in patients with atrioventricular septal defect. We have demonstrated that valve implantation through a left atriotomy is feasible and does not affect pulmonary vein return.

\section{CONCLUSIONS}

We present our experience with the first use of the Melody valve in the mitral position in low-weight infants (2.7 and $3 \mathrm{~kg}$, respectively), demonstrating as well that implantation through a left atrial approach is achievable. The two procedures were performed safely without complications and provided excellent hemodynamic results in the short term. Shortening the length of the stent to $2 \mathrm{~cm}$ is vital to the success of implanting the Melody valve in very small ventricles, virtually eliminating the risk of either left ventricular outflow or pulmonary vein obstruction. The Melody valve is an attractive option for low-weight infants with very small annular diameters.

\section{References}

1. van Doorn C, Yates R, Tsang V, deLeval M, Elliott M. Mitral valve replacement in children: mortality, morbidity, and hemodynamics status up to medium term follow up. Heart. 2000;84:636-42.

2. Selamet Tierney ES, Pigula FA, Berul CI, Lock JE, del Nido PJ, McElhinney DB. Mitral valve replacement in infants and children 5 years of age or younger: evolution in practice and outcome over three decades with a focus on supra-annular prosthesis implantation. J Thorac Cardiovasc Surg. 2008;136:954-61. 961.e1-3.

3. Abdullah I, Ramirez FB, McElhinney DB, Lock JE, del Nido PJ, Emani S. Modification of a stented bovine jugular vein conduit (melody valve) for surgical mitral valve replacement. Ann Thorac Surg. 2012;94:e97-8.

4. Hofmann M, Dave H, Hübler M, Kretschmar O. Simplified surgical-hybrid Melody ${ }^{\circledR}$ valve implantation for paediatric mitral valve disease. Eur J Cardiothorac Surg. 2015;47:926-8.

5. Quiñonez LG, Breitbart R, Tworetsky W, Lock JE, Marshall AC, Emani SM. Stented bovine jugular vein graft (Melody valve) for surgical mitral valve replacement in infants and children. J Thorac Cardiovasc Surg. 2014;148: 1443-9. 